\title{
Application of Laser Ionization Time-of-Flight Mass Spectrometry for the Direct Measurement of a Silane Coupling Agent in Slurries
}

\author{
Takaaki FUJII and Tomohiro UCHIMURA ${ }^{\dagger}$ \\ Department of Materials Science and Engineering, Graduate School of Engineering, University of Fukui, \\ 3-9-1 Bunkyo, Fukui 910-8507, Japan
}

\begin{abstract}
Laser ionization time-of-flight mass spectrometry (LI-TOFMS) was applied to the direct measurement of a silane coupling agent in slurries. In the present study, a slurry with dispersed $\mathrm{TiO}_{2}$ nanoparticles treated with phenyltriethoxysilane (PTES) was prepared. As a result, the peaks for PTES could be observed from the slurry sample containing unreacted PTES, and no peaks were observed from the slurry sample where unreacted PTES was removed by washing. This method can be used to directly analyze surface coating agents, such as PTES in slurries, and would be useful for obtaining a direct understanding of the characteristics of slurries.
\end{abstract}

Keywords Silane coupling agent, slurry, LI-TOFMS, nanoparticles

(Received September 6, 2016; Accepted October 17, 2016; Published March 10, 2017)

\section{Introduction}

Slurries are mixtures where particles are dispersed in a liquid; they are used in a wide variety of commercial products, such as inks, paints and cosmetics. ${ }^{1}$ In the case of metal oxide nanoparticles in slurries, the surface is often coated by organic compounds, such as silane coupling agents, in order to enhance the dispersibility. ${ }^{2}$ In general, unreacted organic compounds for surface coating are then removed from a slurry by washing. Several analytical techniques are applied to evaluate metal oxide nanoparticles modified with organic compounds, which amounts to thermogravimetric (TG) analysis of the weight of organic coatings $^{3-5}$ and diffuse reflectance infrared Fourier transform (DRIFT) spectroscopy for the analysis of interactions between organic compounds and metal oxides..$^{5-8}$ On the other hand, information directly obtained from slurries, such as viscosity of a slurry ${ }^{9}$ and the diameter of particles, ${ }^{10}$ is limited at present. Therefore, analytical methods that can offer information of constituents, such as unreacted agents that remain in slurries without pretreatment or separation, are important for a direct understanding of the characteristics of slurries.

Laser ionization time-of-flight mass spectrometry (LITOFMS), which is a selective analytical process for gas samples in general, ${ }^{11-19}$ is very robust against contamination. That is to say, LI produces fewer contaminants, such as the generation of soot, which is often serious in the case of electron ionization (EI). Moreover, even if the apparatus is contaminated, it can easily be cleaned owing to the simple structure of TOFMS. Until now, LI-TOFMS has been applied to the online monitoring of several environmental samples, ${ }^{19-21}$ and has also been applied to the analysis of compounds generated by heating and/or laser desorption from several types of samples, such as amino acids/

$\dagger$ To whom correspondence should be addressed.

E-mail: uchimura@u-fukui.ac.jp peptides, ${ }^{22-24}$ polymers/oligomers, ${ }^{25-29}$ and particles. ${ }^{30-32}$

Recently, we applied this method to the measurement of pyrolysis products from samples of dried titanium dioxide $\left(\mathrm{TiO}_{2}\right)$ nanoparticles coated by phenyltriethoxysilane (PTES), ${ }^{33}$ which is one of the silane coupling agents. In that report, an oven for a gas chromatograph (GC) was used to gradually heat samples, and benzene was detected as the main product along with several organic compounds. In addition, we also applied LI-TOFMS to the measurement of liquid samples, ${ }^{34,35}$ including emulsions. ${ }^{36-39}$

In the present study, we treated $\mathrm{TiO}_{2}$ nanoparticles with PTES and prepared slurry samples where PTES either remained or was removed by washing. Then, a direct mass analysis of the slurries was performed by LI-TOFMS, and we confirmed whether the remaining PTES could be detected.

\section{Experimental}

\section{Reagents and sample preparation}

$\mathrm{TiO}_{2}$ nanoparticles (rutile, mean particle diameter $260 \mathrm{~nm}$ ) and ethanol were purchased from Wako, and PTES was purchased from Shin-Etsu Silicone.

The sample-preparation procedure of $\mathrm{TiO}_{2}$ nanoparticles treated with PTES was as follows: first, $2.1 \mathrm{~mL}$ of PTES was added to a mixture of $4 \mathrm{~mL}$ of water and $36 \mathrm{~mL}$ of ethanol, and the solution was stirred for several hours by a stirrer in order to hydrolyze the PTES. Next, $336 \mathrm{mg}$ of $\mathrm{TiO}_{2}$ nanoparticles were added to $20 \mathrm{~mL}$ of the above-mentioned solution. The sample was sonicated for $10 \mathrm{~min}$ to disperse the $\mathrm{TiO}_{2}$ nanoparticles, and dried for half a day at $70^{\circ} \mathrm{C}$. Furthermore, it was dried at $70^{\circ} \mathrm{C}$ in vacuo for $6 \mathrm{~h}$ to completely remove the water and ethanol, which resulted in a pasted sample.

In the present study, two types of slurry samples were prepared, i.e., slurries containing unreacted PTES or not. The slurry containing unreacted PTES was simply prepared by 


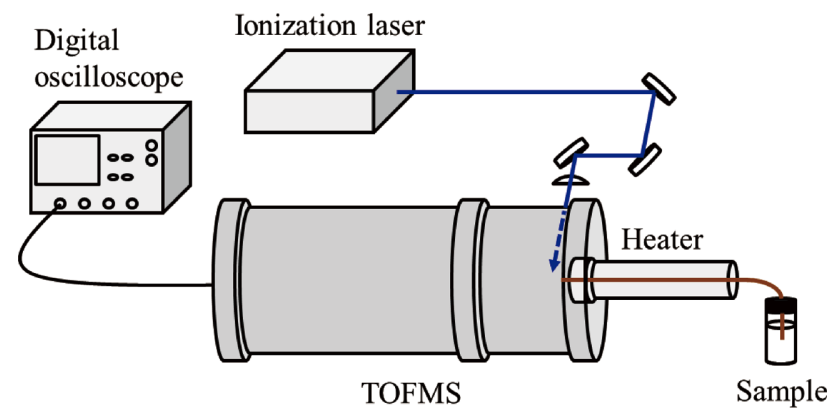

Fig. 1 Experimental apparatus.

dispersing $49.0 \mathrm{mg}$ of the paste in $12.4 \mathrm{~mL}$ of ethanol. For preparation of the latter slurry, however, the paste was first washed by a solvent as follows. First, a certain amount of ethanol ( $c a .1 .5 \mathrm{~mL})$ was added to the paste and it was sonicated for $5 \mathrm{~min}$. After centrifugation at $5000 \mathrm{rpm}$ for $5 \mathrm{~min}$, the supernatant was discarded by decantation. The same process was carried out once again. The obtained sample was then dried in vacuo to completely remove the ethanol solvent. Finally, $11.9 \mathrm{~mL}$ of ethanol was added to $46.9 \mathrm{mg}$ of the obtained $\mathrm{TiO}_{2}$ nanoparticles to prepare the washed slurry sample.

We confirmed that it was difficult to disperse the washed $\mathrm{TiO}_{2}$ nanoparticles in water by comparing with untreated ones, probably because the surface of each $\mathrm{TiO}_{2}$ nanoparticle was modified by hydrophobic organic molecules.

\section{Apparatus}

A schematic diagram of the apparatus is shown in Fig. 1. A slurry sample was introduced into a TOFMS through a deactivated fused-silica capillary column $(50 \mathrm{~cm}$ in length, i.d., $50 \mu \mathrm{m}$, o.d., $150 \mu \mathrm{m}$, GL Sciences). Before introduction, the slurry was sonicated for $5 \mathrm{~min}$ in order to disperse the $\mathrm{TiO}_{2}$ nanoparticles. The sample flowing through the capillary column (30 cm in length) was heated at $300^{\circ} \mathrm{C}$.

The LI-TOFMS system used in the present study is described elsewhere. ${ }^{34}$ In brief, $266 \mathrm{~nm}$ pulses $(4 \mathrm{~ns}, 10 \mathrm{~Hz}, 40-50 \mu \mathrm{J})$ from a Nd:YAG laser (GAIA II, Rayture Systems) were used for the LI. The laser pulses were focused by a lens (focal length $20 \mathrm{~cm}$ ). A linear-type TOFMS (drift length $60 \mathrm{~cm}$ ) was employed in the present study; this system is now commercially available (HGK-1, Hikari-GK, Fukuoka). The ionization point was set at $2 \mathrm{~mm}$ from the tip of the capillary column. The pressure of the chamber was $1 \times 10^{-3} \mathrm{~Pa}$ during the experiments. The ion signals were recorded using a $1-\mathrm{GHz}$ digital oscilloscope (TDS5104, Tektronix). The mass spectra reported in the present study represent the averages of 200 single-shot acquisitions. The detection limit of PTES in ethanol was $100 \mathrm{ng} / \mu \mathrm{L}$ in the present study.

\section{Results and Discussion}

First, an unwashed slurry sample, where unreacted PTES remained, was measured by LI-TOFMS. Figure 2 shows the obtained mass spectrum. The molecular ion peak for PTES $(m / z, 240)$ and several fragment ion peaks appear in the figure. These peaks have also been observed when a vapor of the standard PTES was measured. ${ }^{33}$ Therefore, the obtained peaks arose from the PTES remaining in the slurry sample, which was not hydrolyzed and, therefore, was not reacted with the surface of the $\mathrm{TiO}_{2}$ nanoparticles. In this manner, the present technique

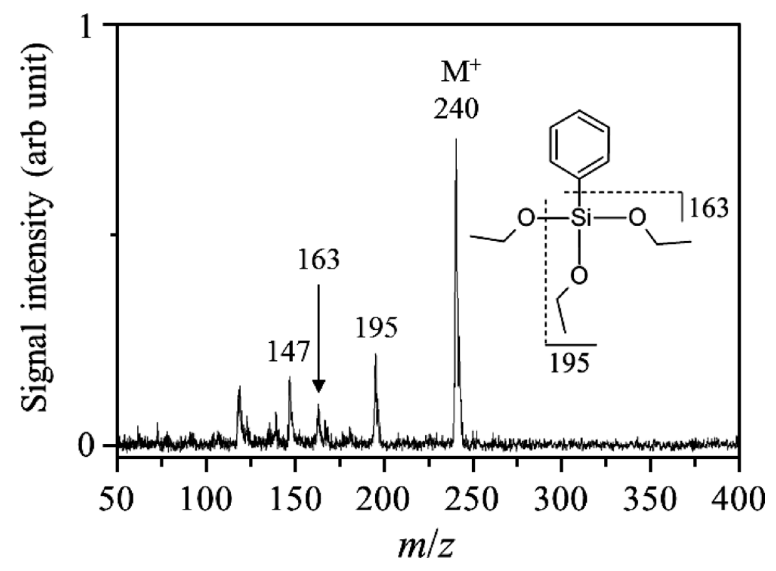

Fig. 2 Mass spectrum obtained by measuring a sample of unwashed $\mathrm{TiO}_{2}$ slurry, where PTES remained.

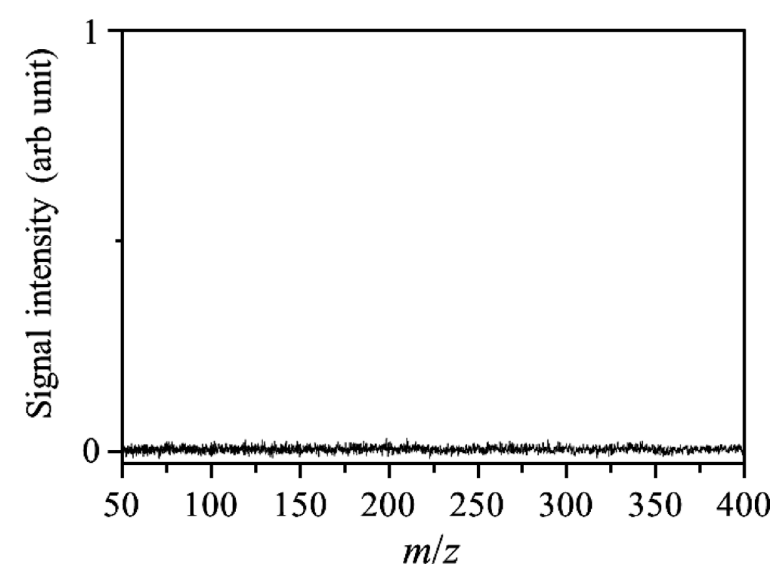

Fig. 3 Mass spectrum obtained by measuring a sample of the washed $\mathrm{TiO}_{2}$ slurry.

can be used to directly detect unreacted silane coupling agents that remain in slurries.

Next, a washed slurry sample where the unreacted PTES was removed was measured. The obtained mass spectrum is shown in Fig. 3; in this case no peaks were observed. For verification, we used an optical microscope to preliminarily confirm the flow of the slurry sample with a white turbidity through the capillary column that was connected with an aspirator. These results indicated that the unreacted PTES was surely removed from the slurry sample by washing, and it could be directly confirmed by LI-TOFMS. Therefore, the degree of slurry washing was directly evaluated by using the present technique. This method can be used to directly analyze surface coating agents, such as PTES in slurries and, therefore, it would be useful for a direct understanding of the characteristics of slurries.

In the present study, no peaks could be confirmed arising from the pyrolysis products originating from the surface of the coated $\mathrm{TiO}_{2}$ nanoparticles, as shown in Fig. 3. Several pyrolysis products were detected when the dried $\mathrm{TiO}_{2}$ nanoparticles coated by PTES, rather than in a slurry, were heated. ${ }^{33}$ When applying gradual heating by a GC oven, benzene, which was a main pyrolysis product, was first observed at $300^{\circ} \mathrm{C}$, and the signal intensity was maximized at $450^{\circ} \mathrm{C}$. In future studies, we will determine whether the pyrolysis products, such as benzene, can be detected when applying temperatures higher than those 
used in the present study. With regard to the detection of benzene, it is effective when the laser wavelength for LI is adjusted to the resonance wavelength for excitation. ${ }^{19}$ Such measurements would be useful for direct evaluations of coated metal nanoparticles in slurries.

\section{Acknowledgements}

Financial support from the Inter-University Network for Common Utilization of Research Equipment is gratefully acknowledged.

\section{References}

1. "Slurry Handling: Design of Solid-Liquid Systems", ed. N. P. Brown and N. I. Heywood, 1991, Elsevier Applied Science, London.

2. N. Nakayama and T. Hayashi, Colloid Surf. A, 2008, 317, 543.

3. X. W. Li, R. G. Song, Y. Jiang, C. Wang, and D. Jiang, Appl. Surf. Sci., 2013, 276, 761.

4. R. Yamazaki, N. Karyu, M. Noda, S. Fujii, and Y. Nakamura, J. Appl. Polym. Sci., 2016, 133, 43256.

5. I. Freris, D. Cristofori, P. Riello, and A. Benedetti, $J$. Colloid Interface Sci., 2009, 331, 351.

6. S. J. Lee, S. W. Han, M. Yoon, and K. Kim, Vib. Spectrosc., 2000, 24, 265.

7. T. C.-K. Yang, S.-F. Wang, S. H.-Y. Tsai, and S.-Y. Lin, Appl. Catal. B, 2001, 30, 293.

8. M. M. Natile and A. Glisenti, Chem. Mater, 2002, 14, 3090.

9. S. K. Kawatra, A. K. Bakshi, and M. T. Rusesky, Miner. Eng., 1996, 9, 881.

10. P. J. Coghill, M. J. Millen, and B. D. Sowerby, Miner. Eng., 2002, 15, 83 .

11. T. Uchimura and T. Imasaka, Anal. Chem., 2000, 72, 2648.

12. J. L. Lin, C.-J. Huang, C.-H. Lin, and W. B. Tzeng, J. Mol. Spectrosc., 2007, 244, 1.

13. A. Hamachi, T. Okuno, T. Imasaka, Y. Kida, and T. Imasaka, Anal. Chem., 2015, 87, 3027.

14. S.-Y. Lu, Q.-L. Wang, W. R. Stevens, C. W. Lee, B. K. Gullett, and Y.-X. Zhao, Appl. Catal. B, 2014, 147, 322.

15. K. Titze, T. Zollitsch, U. Heiz, and U. Boesl, Chem. Phys. Chem., 2014, 15, 2762.

16. J. Miles, S. De Camillis, G. Alexander, K. Hamilton, T. J.
Kelly, J. T. Costello, M. Zepf, I. D. Williams, and J. B. Greenwood, Analyst, 2015, 140, 4270.

17. R. Zimmermann, Anal. Bioanal. Chem., 2013, 405, 6901.

18. J. Kleeblatt, B. Stengel, C. Radischat, J. Passig, T. Streibel, O. Sippula, R. Rabe, H. Harndorf, and R. Zimmermann, Anal. Methods, 2015, 7, 3608.

19. R. Tembreull, C. H. Sin, P. Li, H. M. Pang, and D. M. Lubman, Anal. Chem., 1985, 57, 1186.

20. Y. Kambe, Y. Yamamoto, H. Yamada, and K. Tonokura, Chem. Lett., 2012, 41, 292.

21. R. Zimmermann, R. Hertz-Schünemann, S. Ehlert, C. Liu, K. McAdam, R. Baker, and T. Streibel, Anal. Chem., 2015, 87, 1711.

22. F. Engelke, J. H. Hahn, W. Henke, and R. N. Zare, Anal. Chem., 1987, 59, 909.

23. R. Tembreull and D. M. Lubman, Anal. Chem., 1987, 59, 1003.

24. K. R. Wilson, M. Jimenez-Cruz, C. Nicolas, L. Belau, S. R. Leone, and M. Ahmed, J. Phys. Chem. A, 2006, 110, 2106.

25. T. Streibel, J. Weh, S. Mitschke, and R. Zimmermann, Anal. Chem., 2006, 78, 5354.

26. M. S. de Vries and H. E. Hunziker, J. Photochem. Photobiol. A, 1997, 106, 31.

27. C.-H. Lin, Y. Murata, and T. Imasaka, Anal. Chem., 1996, 68,1153

28. H. Yamamoto, A. Yamakoshi, T. Tsukatani, T. Fujii, and T. Uchimura, Chromatographia, 2015, 78, 1499.

29. R. Kusaka, Y. Inokuchi, and S. S. Xantheas, T. Ebata, Sensors, 2010, 10, 3519.

30. S. Sakurai and T. Uchimura, Anal. Sci., 2014, 30, 891.

31. K. Ohishi, T. Sakamoto, J. Saikawa, N. Ishigaki, K. Tojo, Y. Ido, S. Hayashi, S. Ishiuchi, K. Misawa, and M. Fujii, Anal. Sci., 2013, 29, 291.

32. N. Itouyama, T. Matsui, S. Yamamoto, T. Imasaka, and T. Imasaka, J. Am. Soc. Mass Spectrom., 2016, 27, 293.

33. T. Fujii and T. Uchimura, Anal. Methods, 2015, 7, 2611.

34. G. Tokumoto, H. Saburi, S. Miyagawa, and T. Uchimura, Bunseki Kagaku, 2013, 62, 595.

35. T. Uchimura, G. Tokumoto, O. Batnyam, C.-W. Chou, and S. Fujita, Anal. Sci., 2016, 32, 255.

36. H. Ishigami, Y. Tsuda, and T. Uchimura, Anal. Methods, 2014, 6, 5615.

37. H. Fukaya, Y. Tsuda, and T. Uchimura, Anal. Methods, 2016, 8, 270.

38. Y. Tsuda and T. Uchimura, Anal. Sci., 2016, 32, 789.

39. Y. Shimo and T. Uchimura, Anal. Sci., 2016, 32, 1059. 